\title{
Systems Thinking in Systems Engineering
}

\author{
Fanny Camelia \\ School of Engineering \\ Mawson Lakes Campus \\ University of South Australia \\ Mawson Lakes, SA 5095 \\ fanny.camelia@mymail.unisa.edu.au
}

\author{
Timothy L. J. Ferris \\ Centre for Systems Engineering \\ Cranfield University \\ Defence Academy of the United Kingdom \\ Shrivenham, SN6 8LA \\ timothy.ferris@cranfield.ac.uk
}

Copyright () 2016 by Fanny Camelia and Timothy L. J. Ferris. Published and used by INCOSE with permission.

\begin{abstract}
Systems thinking (ST) offers a holistic approach rather than a reductionist approach, through appreciating all the interrelated dimensions of complex problems. It is important for understanding and interacting with all kinds of systems, in order to manage complex problems. However, the broad range of the ST-related literature found in various disciplines, generates a great deal of disagreement about definitions and understanding of systems thinking. Despite the current ambiguities of ST definitions, its underlying philosophy has a long history. This paper aims to clarify what ST is in the modern day and why it is defined in so many different ways. It identifies a number of interpretations of systems thinking with the purpose of clarifying what it is and why it is variously understood. The main aims of this paper is to propose a new ST construct, and to define its role in the practice of Systems Engineering (SE). This paper then draws implications of the new ST construct for SE education.
\end{abstract}

\section{Introduction}

Systems thinking (ST) serves as a bridge between theory and practice, and between the abstract/intellectual, and concrete/practical domains in systems engineering (SE). It provides a key underpinning for SE and is essential for systems engineers (Godfrey 2010). The philosophy of systems thinking is claimed as a key differentiator of modern SE from technology or application-oriented engineering disciplines (Lamb 2009; Godfrey 2010; Driscoll 2011). ST helps systems engineers to relate systems to their environment, understand situations which encompass complex problem, maximise the satisfaction of achieving desired outcomes and minimise the impacts of unintended consequences (Godfrey 2010). ST is also important in aligning teams, disciplines, specialisms and interest groups as well as in managing uncertainty, risk and opportunity (Godfrey 2010). A study by Frank (2002) asserts that a successful systems engineer must possess a developed capacity for ST.

However, ST related literature is found in various disciplines, including biology, psychology, education, engineering, and sustainability. It is not a central theme in any discipline, however: it is an interdisciplinary discussion (Davidz 2006). The broad range of the ST-related literature found in various disciplines, generates a great deal of disagreement about definitions and understanding of systems thinking. Researchers disagree about what ST is depending on their background discipline (Werhane 2002; Cabrera, Colosi \& Lobdell 2008). Some scholars view it as a science (Richmond 1994), others as a method (Bosch et al. 2007a) and yet others as an approach (Walker et al. 1998). It is also viewed as a skill (Hung 2008), a discipline (Yeo 1993) or a conceptual framework (Cabrera 2006; Cabrera, Colosi \& Lobdell 2008; Kunc 2008; Kapsali 2011). Even relatively new sources such as Arnold and Wade (2015), Whitehead et al. (2015) and Lane (2016) still discuss the ambiguities 
of the ST definition. This research clarifies these ambiguities and clarifies the role of ST in SE and how ST is applied by systems engineers. These different conceptualisations of ST have limited its applicability for educators, practitioners, managers and policy makers (Atwater \& Pittman 2006; Cabrera 2006; Nguyen et al. 2012), including in the SE field. Despite the current ambiguities of ST definitions, its underlying philosophy has a long history. Many scholars regard ST as an ancient concept (Hammond 2003; Wang 2003; Cabrera 2006; Lamb 2009), although the articulation and explicit discussion of ST emerged in the early twentieth century (Luoma 2009). These scholars acknowledge that the conception of ST occurred several thousand years ago, and see it as the mainstream thinking style of cultures from the East.

This paper aims to clarify what ST is in the modern day and why it is defined in so many different ways. It explores the historical and philosophical perspectives underlying ST, discusses the categories found in the ST literature from the early twentieth century. One of the main aims of this paper is to propose a new ST construct, and to define its role in the practice of Systems Engineering (SE). The paper then draws implications of the new ST construct for SE education.

\section{Ancient Philosophy Underlying Systems Thinking}

The ancient ideas of ST emerged several thousand years ago with the beginning of the various philosophical traditions. Systemic thought was embedded in the early cultural traditions from both East and West, and has remained a major intellectual form in the East (Wang 2003). 'East' is not synonymous with Asia, but instead denotes the main part of Asia with the societies which spread geographically across East, Central, North, South, Southeast and West Asia (Barkema et al. 2015). Although, there is great variation among the current nations, states and regions within the Eastern context, Eastern societies broadly share cultural values, spiritual beliefs and philosophies which differ significantly from those in Western contexts (Barkema et al. 2015). 'West' refers to European societies and other societies affected by European culture and imperialism including North America and Australia. The ST view in Western philosophy is evidenced in Heidegger (1973) but was supplanted through the emphasis on entities and their relationships coming through Plato and later Plotinus and the western theologians following Augustine of Hippo, in which the trend of division of whole entities into parts for analysis became clearly evident, and which was pushed to the extreme in the reductionism of Descartes (Checkland 1993; Capra 2010).

Eastern thinking pays more attention to the relations of parts, and the wholeness and interconnections that exist in nature, than the essence of each part (Wang 2003), as is emphasised in later Western thought. The Eastern worldview regards all perceived things and events as interrelated, connected and manifestations of the ultimate reality (Capra 1976; Wang 2003; Capra 2010). This contrasts with the Platonic ideal and Supreme Being as utterly other than the particular manifestations of experience of the world. The human tendency is to divide the perceived world into individual and separate things and to experience self as an isolated ego in the world. This tendency is a pragmatic way to cope with ordinary life, but is contrary to the teaching of most ancient philosophies and religions.

Eastern philosophies are concerned with questions, such as "How can men achieve a harmony with his fellow men?" and "How can man achieve a harmony with nature?" (Koller 1970). This concern contrasts with the modern Western philosophical concern with ontology, epistemology and ethics, all addressed separately, which embodies a fundamentally reductionist perspective.

\section{Systems Thinking Classification}

The underlying ideas of ST are old. The Eastern way of thinking emphasizes the unity and mutual interrelation of all things and events, and has the character of providing a view which emphasises the dynamic of living things and harmony, as well as inseparability of thinking and practice. Although some ancient Greek philosophical threads were close to eastern philosophies, the split began in the fourth $\mathrm{BC}$ with the ascendance of Platonism which separated spirit and matter, leading to a dualism 
which characterized western philosophy and later theology, which, together, provided the intellectual foundation from which the reductionist approach of modern science was developed (Owens 1959; Capra 2010). The notion of an organic, living and spiritual universe was entirely replaced by a world-machine view since the Renaissance. The reductionist and mechanistic way of thinking and analysis has dominated thought and succeeded in delivering classical physics and technology.

The reductionist approach and the scientific method have served society well in the traditional fields of engineering and science. However, although much detail can be studied through this reductionist approach, has been argued that separating a system's elements and analysing each element will limit the analyst's ability to see and understand the overall system (Joseph \& Reigeluth 2010). Scientific enterprises lack an integrative framework to put the pieces back together again. This may led to a misunderstanding of the world at system level that is probably the more important phenomena of life (Nychka \& Kruzic 2013). Thus, at the same time, this way of thinking had many adverse consequences for human civilization and has had limited applicability to complex systems (Kellam, Walther \& Babcock 2009; Capra 2010). One concern is that the reductionist, mechanistic and analytic scientific approach will possibly fail when solving the big problems, that is, when facing extremely complex social phenomena which entail more interacting variables (Capra 2010; Nychka \& Kruzic 2013). Humans need more than incremental improvements in current rationality to manage conflict, collaboration and all forms of relational complexities. Humans need a new thinking-systems thinking - to understand these complexities, joined with new ways of perceiving and visioning their selves, others, nature and the world, a new system with similarities to Eastern thought.

Therefore, in this section, the efforts to articulate systems thinking in the modern age, the categorisation found in the systems thinking literature including the changing paradigms about systems thinking from the early twentieth century were discussed. This discussion is important to appreciate how people perceive systems thinking in the modern age before proposing a new framework for systems thinking to bridge the ambiguities in systems thinking definitions and to understand the role of systems thinking in systems engineering. The effort to articulate this new way of thinking, 'systems thinking' which has been presented under labels such as tektology, General Systems Thinking (GST), cybernetics, and systems of systems theory, has emerged since the early twentieth century.

Before developing the construct of ST and how it applies to SE the categorization and historical development of the ST literature and paradigm evolution from the early twentieth century is discussed. Two fundamental bases for classifying the ST literature as shown in Table 1. Lane and Jackson (1995), Cabrera (2006), and Ramage and Shipp (2009) divide the literature according to the particular theoretical foundation of the work. In contrast Luoma (2009) and Mingers and White (2010) divide the literature according to the purpose of the work. This contrast reflects primary concern to either advance the theory or the application of ST.

In response to the several classifications of the systems thinking literature based on the two fundamental bases to the ST literature can be divided into three branches natural to the motivation for understanding ST in systems engineering. These are:

- theoretical aspects of systems thinking literature

- methodological aspects systems thinking literature-also popular as applied systems thinking (Jackson 2009) — which are developed based on systems thinking theories and frameworks

- practical aspects systems thinking literature, where systems thinking is applied to various areas of concern. (see Table 2)

Those categories derived from Table 1, are compared with three factors identified by Camelia and Ferris (2015) in the analysis of a questionnaire investigating students' learning and appreciation of ST (see Table 2). The two sets of classes, whilst different, are quite similar, indicating a natural structure to this trichotomy. The distinctions between the concepts of theory, methodology and practice of ST 
also map to Checkland's summary of research elements. The elements are the 'framework of ideas' $(\mathrm{F})$, the knowledge of the discipline. The methodology (M), the methods and techniques for using the knowledge. And the 'area of concern' (A), the space to which the knowledge is appropriate to apply (Checkland \& Holwell 1998). These three branches will be discussed below.

Table 1. Summary of Classifications of the Systems Thinking Literature.

\begin{tabular}{|c|c|c|}
\hline $\begin{array}{l}\text { Basis for } \\
\text { classifying ST } \\
\text { literature }\end{array}$ & Scholar & Outline of Classification \\
\hline \multirow{3}{*}{$\begin{array}{l}\text { Classification } \\
\text { according to the } \\
\text { conceptual } \\
\text { foundation of the } \\
\text { work, theories } \\
\text { and } \\
\text { methodologies. }\end{array}$} & $\begin{array}{l}\text { Lane and } \\
\text { Jackson } \\
(1995)\end{array}$ & $\begin{array}{l}\text { Strands of systems thinking are distinguished by aims and } \\
\text { approaches. Eight strands of ST are: General System Theory } \\
\text { (GST); Organisations as systems: Hard systems thinking; } \\
\text { Cybernetics; SD; Soft systems thinking; Emancipatory } \\
\text { systems thinking; and Critical systems thinking. }\end{array}$ \\
\hline & $\begin{array}{l}\text { Cabrera } \\
(2006)\end{array}$ & $\begin{array}{l}\text { - Knowledge about systems (ontological character, } \\
\text { descriptions about systems, conceptual frameworks). } \\
\text { - ST (conceptual and epistemological, concerns a "habit of } \\
\text { mind"), consist of scholarly systems thinking literature and } \\
\text { popular systems thinking literature. }\end{array}$ \\
\hline & $\begin{array}{l}\text { Ramage and } \\
\text { Shipp (2009) }\end{array}$ & $\begin{array}{l}\text { Seven groupings of systems thinking: General Systems } \\
\text { Theory, early Cybernetics, later Cybernetics, SD, Soft and } \\
\text { Critical Systems, Complexity Theory and Learning } \\
\text { Systems. }\end{array}$ \\
\hline \multirow[t]{3}{*}{$\begin{array}{l}\text { Classification } \\
\text { according to the } \\
\text { purpose of the } \\
\text { work. }\end{array}$} & Luoma (2009) & $\begin{array}{l}\text { - Theoretical development of systems thinking. } \\
\text { - Application of ST perspectives and theory in other academic } \\
\text { disciplines. } \\
\text { - Problem solving application of systems thinking. }\end{array}$ \\
\hline & $\begin{array}{l}\text { Mingers and } \\
\text { White (2010) }\end{array}$ & $\begin{array}{l}\text { - Early conceptual development of systems thinking, } \\
\text { 1920s-1960s. } \\
\text { - Development of methodologies and application of systems } \\
\text { thinking, 1970s-1990s. }\end{array}$ \\
\hline & (Wright 2013) & $\begin{array}{l}\text { - Systems thinking theoretical development } \\
\text { - The application of systems thinking methodologies for } \\
\text { practical problems }\end{array}$ \\
\hline
\end{tabular}

\section{Systems Thinking Related Theories and Frameworks}

The first part of the ST literature relates to theories and frameworks which were based on the idea of ST. Although the underlying ideas of ST are old, systematic efforts have been made to articulate systems thinking under labels such as Tektology, GST, cybernetics, and systems of systems theory. This classification did not emerge until the early twentieth century. Since then the meaning of ST has been a topic of scholarly debate. In this section the influential ST theories and frameworks, including the evolution of the paradigm, are explored.

Tektology. Bogdanov's tektology is originally published in the 1910s. It is a general theory of organizations which makes it recognizable as the first theoretical construct of modern ST. It builds on the assumption that all phenomena are governed by organizational laws (Bogdanov 1910; Gorelik 1983). Tektology asserts that any human activity, technical, social, cognitive or artistic, can be 
explored from an organizational viewpoint (Bogdanov 1910; Gorelik 1983). Gorelik (1983) argues that it is still relevant because it has many similarities with modern generalizing sciences and because it is unique as a general theory of organization. It is difficult to assess Bogdanov's direct influence in the West because Western scholars have given more attention to his political activism than his science. However, the resemblance of Bogdanov tektology and the later systems sciences has led many to see his work as prototype for or variant of GST, or a variant of cybernetics.

Table 2. Comparison of the Three Perspectives on the Nature of ST, derived from Table 1, and the Three Factors in the Learning of Systems Thinking Identified by Camelia and Ferris (2015)

\begin{tabular}{|l|l|}
\hline $\begin{array}{c}\text { Perspective on the Nature of Systems } \\
\text { Thinking (Table 1) }\end{array}$ & $\begin{array}{l}\text { Factors in the Learning of Systems Thinking by } \\
\text { Camelia and Ferris (2015) }\end{array}$ \\
\hline ST related theories and frameworks & $\begin{array}{l}\text { Preference or inclination towards whole of systems } \\
\text { perspectives }\end{array}$ \\
\hline $\begin{array}{l}\text { ST related methodologies, (often called } \\
\text { applied systems thinking (Jackson 2009)) }\end{array}$ & $\begin{array}{l}\text { Interest in the intended purpose or application of } \\
\text { the whole system under consideration or } \\
\text { development }\end{array}$ \\
\hline $\begin{array}{l}\text { The practice of using ST to address problems } \\
\text { in various areas of concern }\end{array}$ & $\begin{array}{l}\text { Inclination towards participation in seeking a } \\
\text { coherent, whole, system solution }\end{array}$ \\
\hline
\end{tabular}

Organismic, Open System and General Systems Theory. von Bertalanffy (1968), generally acknowledged as the founder of GST, introduced the organismic, open-system concept and GST to reject the then current and dominant mechanistic and reductionist models in biology and psychology (Hammond 2003). Hammonds explains that von Bertalanffy's idea of the open system, introduced in 1930 emerged when he argued that the second law of thermodynamics can only be applied to closed systems and that living systems require an expansion of traditional thermodynamics (Hammond 2003). He is credited as the first advocate of an 'organismic' approach in biology, in which the characteristic phenomena of life - wholeness, organisation, and regulation - should be considered in a scientific study (Hammond 2003). He argued that an organism cannot be understood by studying its parts and processes using a mechanistic approach. However, it can be understood by discovering the laws of biological systems to which the constituent parts and processes are subordinate. The organismic approach enables recognition of the hierarchy of natural systems and investigation of phenomena at all levels (Hammond 2003).

By linking the open systems concept with his idea of organismic, von Bertalanffy defined the organism as a hierarchy of an open system maintaining itself in steady state due to inherent system conditions (Hammond 2003). He also thought that his system concepts provided a better way to understand complex systems and introduced the GST to provide a heuristic guide for understanding any system through the discovery of universal patterns (Hammond 2003). He believed that GST is applicable across disciplines and could be used to study the human psyche, social institutions and the global ecosphere, where similar laws of organization might apply.

Cybernetics. Cybernetics aims to find similarities in the function of automatic machines and the human nervous system, and then develop a theory to address communication and control in machines and living organisms (Wiener 1948). Cybernetics is a theory of messages and communication through a system and the use of the messages in the self-control of the system. It embeds two concepts: homeostasis and feedback. Although these two concepts cannot explain the phenomena of living systems and humans such as changes, evolution, by incorporating circular forms of causality and highlighting the importance of information and communication in the organization of complex systems, it was regarded as a move beyond the linear causal models of traditional mechanistic thought. This concept opened the way to further discoveries in the chaotic dynamics of nonlinear systems (Checkland 1993; Hammond 2003). 
Many implementations based in cybernetics seek to construct machines which exhibit 'intelligent' behaviours as a means to explore possible mechanism models of the brain (Checkland 1993). It laid the groundwork for later work in artificial intelligence and cognitive science (Hammond 2003). Current applications of cybernetics include bio-cybernetics, biomedical systems, adaptive systems, artificial intelligence, robotics, large-scale socio-economic systems, man-machine systems, and systems science (Johannessen 1998; Rudall 1998; Vallee 2003).

Hierarchy of Complexity. Boulding, an economist, built upon the GST arguing that behaviour of complex phenomena cannot be predicted using the methods applied to simple phenomena (Luoma 2009). By linking the homeostasis of cybernetics with Keynesian economics, he argued that economic life must be understood as an aspect of the whole complex social relationship and assigned regulatory mechanisms to government (Hammond 2003). He introduced a nine level hierarchical map for the comparative study of individuals across disciplines which he called 'systems of system' (Boulding 1956). Boulding asserted that more complex systems need to be studied using methods designed to manage the complexity. Each level in the hierarchy manifests the characteristics of the lower levels as well as new behaviour elements. However, the properties of a system cannot be reduced to the sum of the properties of its parts, that is, the system has emergent properties. Since each level incorporates all the levels below it, much insight can be obtained by applying knowledge of lower level systems to higher level subject matter with the caveat that emergent effects may be found.

Hard Systems and Soft Systems. In 1983 Checkland introduced the distinction of hard and soft systems (Checkland 1983) arguing that the concepts of ST are a particular way of describing the world, not a proposition of what the world is like. This conflicts with earlier systems theorists, such as Boulding, who proposed that the hierarchical organization of systems is part of the real world (Luoma 2009). Checkland's argument (1983) is based on the distinction of three types of systems:

1. Situations or phenomena characterized by interconnections which are inherent in nature.

2. Situations characterized by interconnections derived from the logic of situations.

3. Situations or phenomena characterized by interconnections that are cultural, situations dominated by the meaning observers attribute to their perceptions.

The hard ST paradigm is suitable for use in systems of types 1 and 2 (Checkland 1983). It is linked to a 'positivist perspective', a worldview in which observers are believed to be independent of what is observed, and it is believed 'true' representation of reality is possible (Schwaninger 1997). The hard system perspective asserts that systems have real existence outside the observers. Therefore, the goals of hard systems thinkers are to know about systems and to improve or design systems by applying scientific knowledge. This paradigm is consistent with mathematical systems analysis, empirical systems research, SE, GST and much of natural science.

The soft ST paradigm is useful in type 3 systems. Soft ST approaches are derived from a 'hermeneutic perspective' where people adopt a 'subjectivist view'. In this paradigm it is believed that reality is viewed through individual perspectives and the interrelationships of perspectives must be considered (Schwaninger 1997). Each observer perceives the same external stimuli from his/her point of view but their descriptions differ because of their different 'Weltanschauung' (a German word meaning 'world view'). In soft ST the world is seen as problematic: we cannot know its real structure, ontology. Nevertheless, the process of engaging with it, of trying to understand and/or engineer it, can be systemic (Checkland 1983). The soft systems approach is more subjectivist since it does not seek regularities and causal relations in reality. The world, according to soft systems thinkers, is an artefact created by the collective subjectivity of humans (Nodoushani 1991).

Critical Systems Thinking. By the 1980s there were many hard and soft system approaches and a new question emerged: which method should be used and when (Jackson 1989). At the same time a third paradigm in ST known as CST developed (Ulrich 1983; Jackson 1985; Mingers \& White 2010). Critical systems thinking, CST, is a relatively new, and rapidly developing, approach in ST (Jackson 
1991). CST refers to a range of research and practice (Flood 2010) and is inspired by social theory (Jackson 2001). The epistemological debate around CST eventually moved from selecting a single method to how to combine methods, including hard and soft, in a form known as multi-methodology or coherent pluralism (Mingers \& White 2010). It is argued that this allows the practitioner to address both the quantitative and qualitative aspects of a complex situation and that combining methods can better address the different phases of an intervention (Mingers \& White 2010). There is no single approach or set of principles that defines CST but practitioners achieve integrity in their diversity through several core commitments (Flood 2010) by bringing appropriate methodologies and tools to bear on problem situations (Jackson 2001). The core commitments of CST are: critical awareness, social awareness, complementarism at the methodological level, complementarism at the theoretical level and dedication to human emancipation (Jackson 1991).

\section{Systems Thinking Related Methodologies}

ST literature also discusses methodologies suited to different theoretical rationales focused on improving some real-world situations, and are known as applied ST (Jackson 2000; Jackson 2006, 2009; Flood 2010). Each application of the methodologies should exhibit reasoning about how to adapt to the circumstances (Jackson 2001). The ST methodologies can be divided into functionalist, interpretative and emancipatory methodologies (Jackson 2001).

Functionalist Methodology. Functionalist methodologies use mechanistic or organismic models which adopt hard ST perspectives and early ST theories. Organismic models, also known as structuralist methodologies, are sometimes differentiated from other functionalist methodologies. Both mechanistic and organismic models assume the world is systemic. Both mechanistic and structuralist models enable intervention based on expert knowledge and solutions are evaluated in terms of efficiency and efficacy. Because of these similarities we discuss them together in this paper.

Functionalist methodologies aim to capture the logic of the situation and to use that to generate a representation of the system which can be used to understand the relationships within the system and through that to make predictions about system behaviour under particular conditions. Prediction is desired because it enables planning of interventions to have desired effects, and in the case of functionalist methods quantitative modelling is most common (Jackson 2001).

Examples of functionalist methodologies which adopt mechanistic model are 'systems analysis' (SA) and SE. These approaches employ analytic models to capture the most important variables and interactions in the system of concern, and to determine the most efficient way of reaching the goal. Moreover, examples of functionalist methodologies which adopt organismic models are 'systems dynamics' (Forrester 1971), 'learning organizations' (Senge 2006) and 'organizational cybernetics' (Beer 1979). These methods enable examination of the effect of intervention design controlled variables to predict desirable interventions. Other approaches which use a mechanistic formulation of systemic issues include: 'operations research' (Checkland 1993); 'Systems Modeling Language' (SysML); 'Structure Query Language' (SQL); 'Six Sigma'; 'Arena'; 'Unified Modeling Language' (UML); 'IDEF0'; and 'Architecture Frameworks' (Whitehead, Scherer \& Smith 2014). Many of these are tools which are used in the practice of SE.

Interpretative Methodologies. Interpretive methodologies were established in the US and UK by systems thinkers seeking understanding of human and social systems at the higher levels of Boulding's hierarchy (Jackson 2009). In the US, Ackoff and Churchman developed 'social systems sciences' and 'social systems design', respectively, while in the UK, Checkland, developed 'soft systems methodology' to deal with ill-structured problem situations with highly interdependent elements (Jackson 2009). These approaches are called interpretive methodologies because they build on stakeholder interpretations of reality. The plurality of interpretations accommodates the different values, beliefs, philosophies and interests of multiple parties. 
In contrast with functionalist methodologies, interpretative methodologies do not assume that the world is systemic. The interpretive methods construct models to assist interrogation of perceptions of the world and to structure debate about feasible and desirable interventions (Jackson 2001). The process of intervention is seen as systemic, continuing, and is aimed at alleviating unease about the problematic situation rather than providing a solution, and is conducted using stakeholder participation (Jackson 2001). Interventions that may alleviate unease are evaluated in terms of effectiveness, elegance and ethics (Jackson 2001).

Emancipatory Methodologies. Problems arise in applying interpretative methodologies if stakeholders have little in common and compromise is difficult to achieve. In such cases decisions are dominated by those with power, resulting in potentially unfair outcomes (Jackson 2009). Emancipatory methodologies assume that the systems that develop in the world can alienate individuals and/or groups (Jackson 2001). Analysis of a situation aims to show who is disadvantaged in the current situation. Models which reveal alienation and disadvantage are used to enlighten the alienated about their situation and to suggest possible improvements (Jackson 2001). Such proposed changes are evaluated in terms of ethicality and emancipation. Ulrich's 'critical systems heuristics' (1983) presents questions to be asked to identify who benefits from particular systemic situations and seeks to empower those excluded from positions of power (Ulrich 1983). Meanwhile, Beer's 'team syntegrity' (1994) seeks to specify an arena and procedures that enable all stakeholders to debate openly and democratically the issues with which they are confronted.

\section{Practice of Systems Thinking for Problem Solving}

The largest portion of the systems thinking literature focuses on the application of systems thinking in various areas. It is not practical to cover the literature of ST which engage with and address a wide range of issues, since it spans many fields of interest. However, in brief, the literature on the practice of ST can be divided into two areas of application:

1. the established ST-related methodology, tools and methods, such as soft systems methodology, systems dynamics, cybernetics, applied to solve problems in various areas of concern

2. ST as a conceptual understanding of problem solving in the various areas of concern and academic disciplines which have become the basis for the development of frameworks.

It can be summarised that the influential earlier ST literature emphasised learning about systems in the world by introducing frameworks, ideas and principles about systems. Other systems thinkers concentrated on developing methodologies, based on the ideas and principles of the system, in order to make interventions. These two groups of literature share similar assumptions about the nature of systems. For example, ideas about SST were adopted to develop SST methodology. Meanwhile, the later ST literature, the largest part of the ST literature, mostly focused on the practice of ST, as a method or approach as well as a conceptual understanding, with useful results applied to a wide variety of practical situations of interest.

It is understandable that a broad range of ST literature led to disagreements about what systems thinking is. ST can be associated with a specific ST theoretical framework such as tektology, general systems theory (GST), cybernetics, hierarchy of complexity, hard and soft systems thinking or critical systems thinking. ST can correspond to a specific systems thinking method or approach such as:

- functionalist ST methodologies-systems analysis (SA), systems engineering (SE), systems dynamic (SD), viable systems model (VSM)

- interpretative ST methodologies - soft systems methodology, social systems sciences, social systems design

- emancipatory ST methodologies — critical systems heuristics and team syntegrity.

This broad range of ST literature also led to introducing ST as a science (Richmond 1994) or a discipline (Yeo 1993; Wright 2013) because ST has rigorous frameworks, methodologies and 
applications (Gorelik 1983; Kline 1995). The proficiency needed to implement ST resulted in ST also being known as a skill (Sterman 2000; Hung 2008; Brandstädter, Harms \& Großschedl 2012; Arnold \& Wade 2015) or a competency (Systems Engineering Competencies Working Group INCOSE-UK 2010). However, these characteristics found in the systems thinking literature do not explain what systems thinking really is. Therefore, another question emerges: "What is ST?". In addressing this question, the next section proposes that that systems thinking is a conceptual understanding or mental construct.

\section{Systems Thinking as a Mental Construct: A Proposed Framework}

Based on the discussion about systems thinking classification in the previous section, the relationships of the systems thinking categories of the literature can be mapped as presented in Figure 1.

The most important role of systems thinking in the literature is as a conceptual understanding. This conceptual understanding is derived from the established systems thinking related theories and frameworks which also have become the basis for developing systems thinking methodologies, methods or approaches, including systems engineering. This conceptual understanding is applied in various disciplines, then becomes the basis for developing newer theories and frameworks, which can later be developed into new methodologies in various areas of concerns.

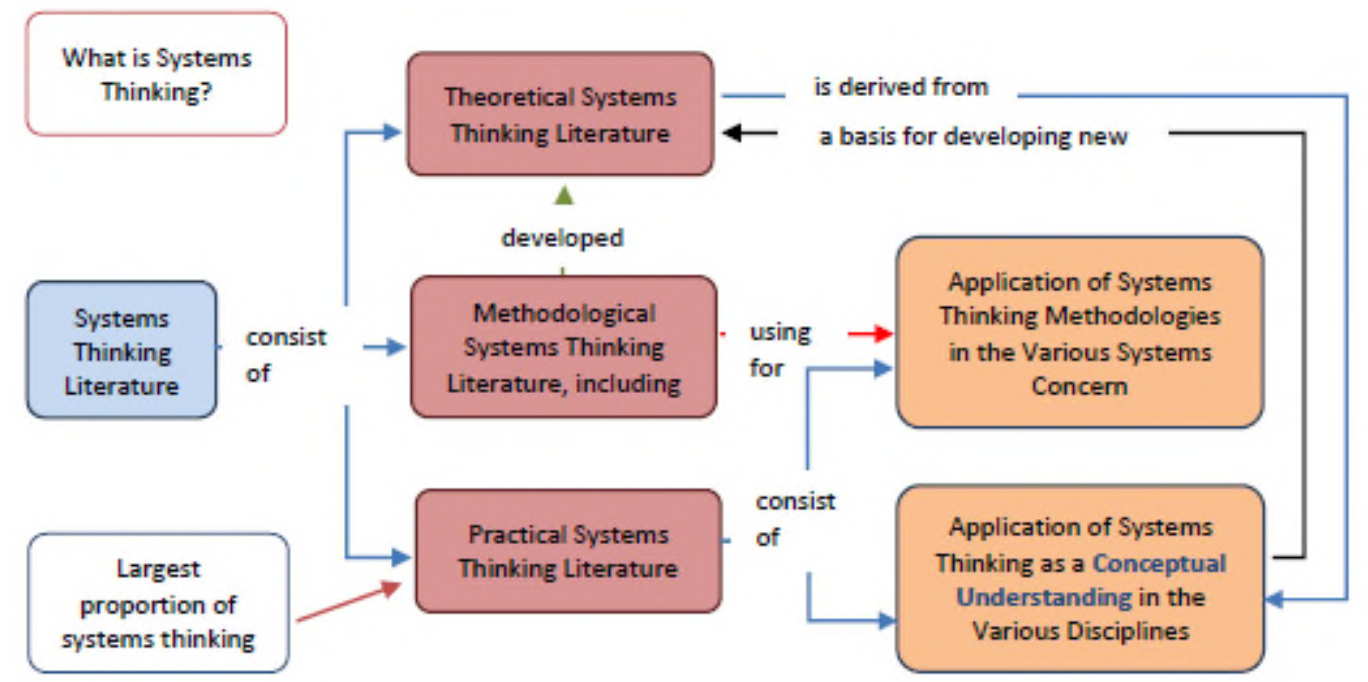

Figure 1. Mind Map of the Relationship of Systems Thinking Categories in the Literature

ST is not a specific ST theory or framework, nor a particular methodology or plurality of methods (Cabrera 2006; Cabrera, Colosi \& Lobdell 2008; Kapsali 2011; Cabrera, Cabrera \& Powers 2015). Building on the definition given by Cabrera (2006), ST is a conceptual understanding or a mental construct for thinking about and learning about and interacting with all kinds of systems, including scientific, organizational, personal and public systems. This view of ST, related to being systemic in the way humans conceptualize has more in common with work of Ackoff (1981), Churchman (1971) and Checkland (1993) than the systems view that assumes systems are real-world phenomena and our knowledge reflects this reality, following the work of M'Pherson (M'Pherson 1974) and Laszlo (1971).

As a mental construct, when learning about a systems phenomenon, a systems thinker recursively applies ST rules to change, eliminate or create new constructs until an internally consistent construct, which becomes the conclusion of the investigation, is achieved (Cabrera 2006; Trochim et al. 2006; Cabrera, Colosi \& Lobdell 2008). Systems thinkers apply several rules of ST in their observation and interpretation of system phenomena, including:

1. Question the system boundary, for example in Cabrera, Cabrera, and Powers (2015), Cabrera (2006), Kapsali (2011). 
2. Question the system structure, including parts, hierarchy, whole, for example in Mingers and White (2010), Kunc (2008), Brandstädter, Harms, and Großschedl (2012).

3. Question the interrelationships within the system, including feedback for example in Richmond (1994), Hung (2008), Schiuma, Carlucci, and Sole (2012).

4. Adopt multiple points of view, for example in Cabrera, Cabrera, and Powers (2015), Cabrera (2006), Kasser, Frank, and Zhao (2010).

5. Consider change over the time (dynamic characteristics) for example in Capra (2010), Capra (1982), Davidz (2006).

6. Apply holistic and big picture view for example in Kasser, Frank, and Zhao (2010), Bosch (2007b) and Gharajedaghi (2006).

These rules have been extracted from patterns across the ST literature. More specifically, some of the more popular ST approaches are:

- Ulrich's critical systems heuristics (1983) which prioritises the exploration of boundaries (first rule)

- the viable system model of Beer (1979) which examines organisations in terms of nested systems (second rule)

- the system dynamics of Forrester (1971) which prioritises the modelling of relationships (third rule)

- the soft systems methodology of Checkland (1990) which is primarily about exploring and representing different perspectives (fourth rule) (Midgley 2008)

- Capra's (2010) concept about ST and the wholeness style of thinking adopted by the Eastern people which prioritises the dynamic and holistic view (fifth and sixth rules).

Cabrera (2006) proposed that ST only focuses on the conceptualisation process which is called a theory of conceptualisation (Midgley 2008), but neglects the perception process. Considering the old style of thinking and philosophical underpinning of ST, related to how Eastern people perceive the world, it was believed that ST is not only the conceptualisation process but also the perception to the world. Thus, ST can help people to perceive the world, understand how the system works and how to interact with it appropriately.

Cabrera's original proposed ST offered concepts and rules, but no tools and techniques needed to enhance ST and no alignment to ST methods and approaches, except applying these rules more consciously and more regularly. His suggestion that people only need to employ the rules of systems thinking more consciously, rather than suggest to develop new methods or approaches. This view contradicted what Migley (2008) said was the accepted wisdom of the systems community. For over fifty years systems thinking researchers have been creating innovative qualitative and quantitative ST methods which go beyond 'common sense' conceptualisation. Since the 1990s, most scholars have believed that pluralism in the methods adopted is important to enhance systems practice for solving different problems, which was also advocated by CST (Midgley 2008).

Midgley's criticism (2008) of Cabrera's original work suggested that the ST concept can be implemented in two stages of logic: 1) employing ST rules grounded in people's every day thinking, and this can be improved by using these rules more regularly and consciously; and 2) employing a variety of ST methods or designing a new method or approach which consists of a combination of available methods if needed. The second stage of logic also parallels Davidz's view about systems thinking: she holds that practitioners should employ modal elements including a variety of tools, methods and models for enabling understanding of a system (Davidz, Nightingale \& Rhodes 2005; Davidz 2006; Lamb 2009). These modal elements could be the established ST methodology or visualisations tools to model and capture concepts in real systems such as concept maps, mind maps and systemigrams (Boardman 2008).

Therefore, the proposed definition of ST arrived at is: the conceptual understanding or mental constructs of the systems of interest which involve perception and conceptualisation processes by applying systems thinking rules: questioning systems boundary, systems structure and 
interrelationship; adopting multiple perspectives; considering dynamic characteristics; and applying a holistic and big picture view, which can be improved by the use of the most suitable systems thinking tools, methods or approaches.

In the next section, this proposed definition is mapped into the systems engineering discipline. This definition clarifies the role of systems thinking in systems engineering and discusses how it should be applied in systems engineering. This is followed by a discussion about the review of studies of systems thinking in the systems engineering field.

\section{Systems Thinking in Systems Engineering and Its Implication to Systems Engineering Education}

SE has evolved from a step-by-step, science-based engineering methodology into an interdisciplinary approach, a meta-methodology, for providing whole solutions to complex problems. It is a meta-methodology because it engages with technical situations and organizes and manages effort through guiding the appropriate choices of theoretical perspective and methodological perspective to address each part of a project, and encourages the use of whichever method is the most useful for addressing each part of the matter at hand. The characterization of SE as a meta-methodology is consistent with the proposed definition and application of ST above, that ST is a conceptual understanding or a mental construct, which itself is an intellectual structure which frees consideration of ST from the constraint of needing to defend the proposition that it is one particular thing. Rather, the mental construct position results in viewing ST as a concept which organizes the use of perspectives to understand the system at hand and allows the selection of ST theories and methods to deal with parts of the task of interacting with the system for an appropriate result.

SE relies on ST to view the engineered system at the level of a whole system. In a system development project, systems engineering activities focus on development processes, including the decomposition and recomposition processes, by considering the whole processes and the issues within a system's life cycle. Of importance in SE is that throughout the system life cycle, all stakeholders' needs are satisfied. During these two processes, systems engineers need to solve emerging problems, and make decisions. To solve problems and to ensure the decisions involve rational and effective problem solving and are traceable, justifiable decisions, systems engineers need to take a systems perspective, instead of a reductionist approach, hence, every contingency is considered and nothing is abandoned (Buede 2011). By taking a systems perspective, every element of the system receives appropriate attention and a balance of resources in essentially all systems decisions (Kossiakoff \& Sweet 2011). As a consequence, no system attributes would receive more attention than other, similarly important attributes or even the more important attributes (Kossiakoff \& Sweet 2011).

Systems engineers do the work of perceiving and conceptualizing their systems of interest, especially in order to make decisions and solve emergent problems during systems development. They apply ST methods and rules recursively until they obtain an internally consistent construct, which becomes the conclusion of their investigation. The rules are grounded in their everyday thinking but the use of these rules can be enhanced through the more regular and conscious use of these rules. It can be further enhanced by the use of a variety of ST related tools, methods or approaches, including methods which are based on:

- functionalist methodologies such as systems dynamics (Forrester 1971)

- interpretative methodologies such as soft systems methodology (Checkland 1993)

- emancipatory methodologies such as critical system heuristics (Ulrich 1983).

They will also use visualizations tools such as concept maps, mind maps and systemigrams to model the system (Boardman 2008). Alternatively, systems engineers can also design a new method or approach which is the most suitable to a particular system using a combination of the available methods. That is, the application of systems thinking as a conceptual framework can improve the 
effectiveness of the systemic approach in decision making and problem solving during systems engineering processes (see Figure 2).

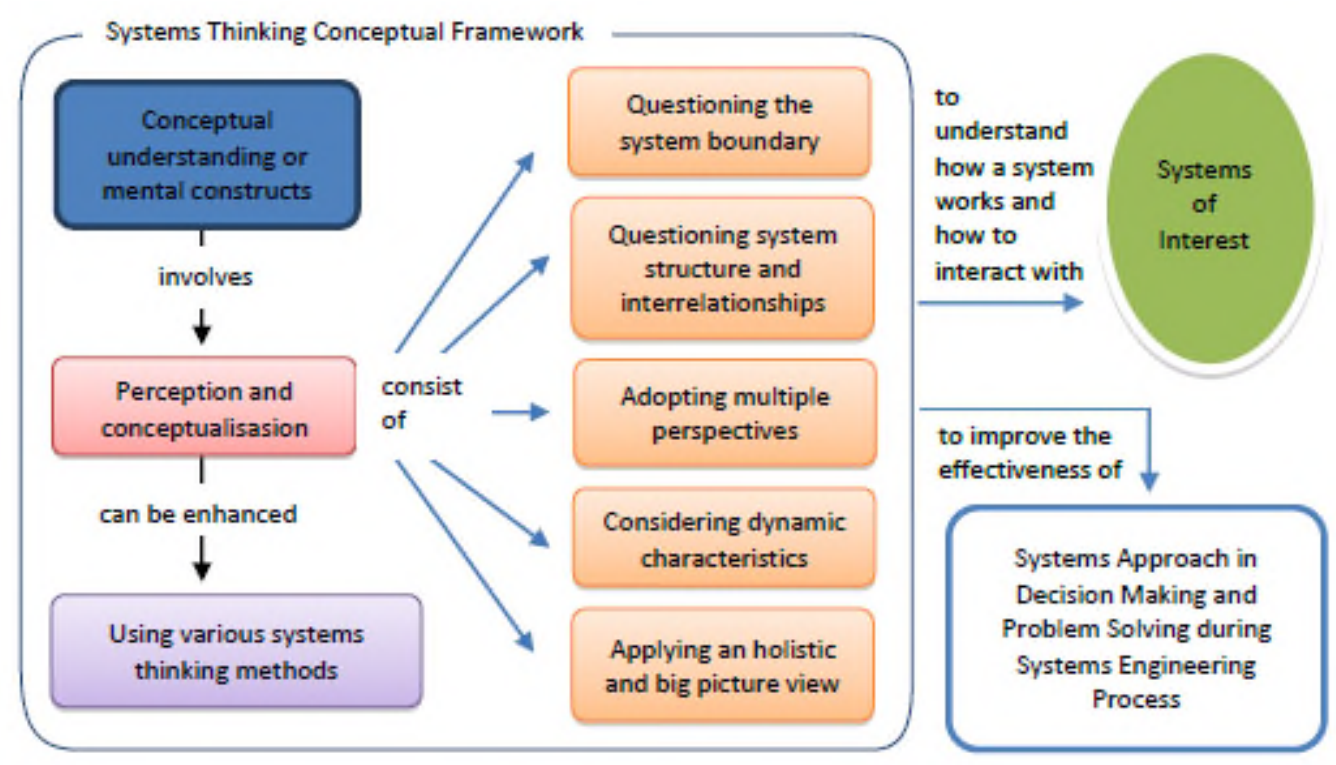

Figure 2. Mind Map of Application of Systems Thinking as a Conceptual Framework during Systems Engineering Process

A systems engineer needs a combination of ability and willingness to conceptualize and perceive the system of interest by using ST as a mental construct when engaging with a system at every stage of SE, performing SE work using the broad range of ST theories and methods and judging which is appropriate to use, and when (Camelia, Ferris \& Cropley 2015). Since ST involves conceptualization of the world, SE educators must establish both the theoretical and methodological aspects of ST in SE students. The theory and methods of ST can be taught with methods focused on the cognitive domain of learning. These are educational methods familiar to most members of the SE community, along with improvements. However, since ST also involves perception of the world, it is affected by the beliefs, values and assumptions that people hold. It follows that the systems engineer will emotionally engage with the cognitive content in a manner influenced by their beliefs and interests, which is the reason that the affective domain is important (Bechara 2004; Coricelli, Dolan \& Sirigu 2007; Quartz 2009; MacFadden \& Schoech 2010).

While cognitive development is necessary so that students develop the essential technical skills to perform tasks effectively, it is also crucial to develop the students' perception of the value of these skills so that their approach to work will be characterised by the exercise of these technical skills. It is important for engineering educators to develop their students in the affective domain in relation to systems thinking so that those students will be characterised by a belief in the power of systems thinking to enable them to develop superior engineered products and systems (Camelia, Ferris \& Cropley 2015). The importance of the affective development of systems thinking is to ensure that students not only become characterised by the use of traditional, reductionist approaches, but also by the use of systems thinking in their approach to engineering activities, even when working under pressure. Thus, one goal of SE education must be the development of the student's affective engagement with the ST subject matter so that the graduate demonstrates a fluent use of ST concepts, structured theories and methods in their practice. The fluency and appropriate use of the ST knowledge depends on commitment to the ST knowledge as a valuable approach for performing work.

\section{Conclusion}

This paper has discussed several main issues in systems thinking within the context of systems engineering. It has reviewed the historical and philosophical perspectives underlying ST and the 
categorisation of the ST literature which has led to a proposed systems thinking conceptual framework. This paper has examined systems thinking in the practice of SE and its implications for SE education, including the need to measure both the cognitive and affective dimensions of student's systems thinking development.

ST has been a major thinking style of thinking since ancient times, with the exception of some threads of Greek philosophy which became dominant during the late pre-Christian period and which then became the dominant strands of philosophy informing the western tradition. The foundation of the modern approach to science, epitomized by the reductionist teachings of Descartes, and the subsequent effectiveness of the reductionist approach in the development of science has led to a tension with the ST emphasis on understanding of things in context and in their wholeness has led to the difficulty for ST to be accepted as a method of thinking in western culture and particularly in science and engineering.

This paper has established how systems thinking is influenced by: six influential theoretical approaches (tektology, general systems thinking, cybernetics, systems complexity hierarchy, hard and soft systems and critical systems thinking); three methodological approaches (functionalist, interpretive and emancipatory); and two practical perspectives of systems thinking (methodologies and conceptual application). Systems thinking has been applied, with useful results, to a wide variety of practical situations of interest.

It is concluded that the most important role of the systems thinking literature is as a conceptual understanding. To clarify the ambiguities of systems thinking definitions, systems thinking can be defined as a conceptual understanding or mental constructs of the systems of interest which involve the perception and conceptualisation processes by applying systems thinking rules, namely: questioning systems boundaries, systems structure and interrelationships, adopting multiple perspectives, considering dynamic characteristics and applying an holistic and big picture view. Systems thinking can be improved by the use of the most suitable systems thinking tools, methods or approaches.

Furthermore, SE is an engineering discipline aiming to deliver solutions that are most appropriate when viewed from a whole systems perspective. That is, the concern of SE is to ensure that what is offered as a solution to a need is, when viewed from all perspectives, the most appropriate solution that can be found. This perspective demands that systems engineers approach their work from a holistic viewpoint. And, therefore, that the systems engineer applies ST to addressing matters of need and concern, especially during decision making and problem solving. Thus, using an ST conceptual framework is the fundamental perspective of the systems engineer, who then uses the methods and techniques described by ST scholars to strengthen their belief in the holistic approach. SE education must address both cognitive capacities and affective engagement in ST and be equipped with suitable tools to measure the development of these capabilities.

\section{References}

Ackoff, R. L. 1981. Creating the Corporate Future: Plan or Be Planned For. New York: Wiley.

Arnold, R. D., and J. P. Wade. 2015. "A Definition of Systems Thinking: A Systems Approach." Procedia Computer Science 44 (2015):669-678.

Atwater, J. B., and P. H. Pittman. 2006. "Facilitating Systemic Thinking in Business Classes." Decision Sciences Journal of Innovative Education 4 (2):273-292.

Barkema, H. G., X.-P. Chen, G. George, Y. Luo, and A. S. Tsui. 2015. "West Meets East: New Concepts and Theories." Academy of Management Journal 58 (2):460-479. 
Bechara, A. 2004. "The Role of Emotion in Decision-Making: Evidence from Neurological Patients with Orbitofrontal Damage." Brain and Cognition 55 (1):30-40.

Beer, S. 1979. The Heart of Enterprise. Chichester: Wiley.

1994. Beyond Dispute: The Invention of Team Syntegrity. Chichester, New York: Wiley.

Boardman, J. T. 2008. Industrial Innovation, Volume 4: Systems Thinking: Coping with 21st Century Problems. Boca Raton, FL, USA: CRC Press.

Bogdanov, A. 1910. "The Historical Necessity and the Scientific Feasibility of Tektology (Originally Published in Russian)." In Systems Thinking, edited by G. Midgey. London: SAGE. Original edition, Bogdanov's Tektology, Book 1, Sadovsky, V.N., Kartashov, A., Kalle, V. and Bystrov, P. (trans.) Dudley, P. (ed), Centre for Systems Studies, Hull, 1996 (Originally published in Russia, 1910-1913).

Bosch, O. J. H., C. A. King, J. L. Herbohn, I. W. Russell, and C. S. Smith. 2007a. "Getting the Big Picture in Natural Resource Management-Systems Thinking as 'Method'for Scientists, Policy Makers and Other Stakeholders." Systems Research and Behavioral Science 24 (2):217-232.

--------. 2007b. "Getting the Big Picture in Natural Resource Management-Systems Thinking as 'Method' for Scientists, Policy Makers and Other Stakeholders." Systems Research and Behavioral Science 24 (2):217-232.

Boulding, K. E. 1956. "General System Theory-the Skeleton of Science." In Systems Thinking, edited by G. Midgley. London, Thousand Oaks, New Delhi: Sage Publications. Original edition, "General Systems Theory-The Skeleton of Science," Kenneth e. Boulding, Management Science, 2, 197-208 (1956).

Brandstädter, K., U. Harms, and J. Großschedl. 2012. "Assessing System Thinking through Different Concept-Mapping Practices." International Journal of Science Education 34 (14):2147-2170.

Buede, D. M. 2011. The Engineering Design of Systems Models and Methods. 2nd ed. Hoboken, N.J: John Wiley \& Sons.

Cabrera, D. 2006. "Systems Thinking." Doctor of Philosophy Dissertation, Faculty of the Graduate School of Cornell University, Cornell University.

Cabrera, D., L. Cabrera, and E. Powers. 2015. "A Unifying Theory of Systems Thinking with Psychosocial Applications." Systems Research and Behavioral Science 32 (5):534-545.

Cabrera, D., L. Colosi, and C. Lobdell. 2008. "Systems Thinking." Evaluation and Program Planning 31 (3):299-310.

Camelia, F., and T. L. J. Ferris. 2015. Undergraduate Students' Engagement with Systems Thinking: Results of a Survey Study. Unpublished

Camelia, F., T. L. J. Ferris, and D. H. Cropley. 2015. Development and Initial Validation of an Instrument to Measure Students' Learning About Systems Thinking: The Affective Domain, in press, Systems Journal, IEEE 99(2015).

Capra, F. 1976. "Modern Physics and Eastern Mystiscism." Journal of Transpersonal Psychology 8 (1). 1982. The Turning Point: Science, Society and the Rising Culture. London: Flamingo. - 2010. The Tao of Physics: An Exploration of the Parallels between Modern Physics and Eastern Mysticism. 5th ed. Boston: Shambhala. 
Checkland, P. 1983. "O.R. And the Systems Movement: Mappings and Conflicts." The Journal of the Operational Research Society 34 (8):661-675.

1993. Systems Thinking Systems Practice. Great Britain: John Wiley and Sons.

Checkland, P., and J. Scholes. 1990. Soft Systems Methodology in Action. Chichester: Wiley

Checkland, P. B., and S. Holwell. 1998. Information, Systems and Information Systems. Chichester: Wiley.

Churchman, C. 1971. The Design of Inquiring Systems. New York: Basic Books.

Coricelli, G., R. J. Dolan, and A. Sirigu. 2007. "Brain, Emotion and Decision Making: The Paradigmatic Example of Regret." Trends in Cognitive Sciences 11 (6):258-265.

Davidz, H. L. 2006. "Enabling Systems Thinking to Accelerate the Development of Senior Systems Engineers." Doctor of Philosophy, Engineering Systems Division, Massachusetts Institute of Technology.

Davidz, H. L., D. J. Nightingale, and D. H. Rhodes. 2005. "Accelerating the Development of Senior Systems Engineers." The 15th Annual International Symposium INCOSE

Driscoll, P. J. 2011. "System Thinking " In Decision Making in System Engineering and Management, edited by G. S. Parnell, P. J. Driscoll and D. L. Henderson, 27-64. New Jersey: A John Wiley and Sons, Inc.

Flood, R. L. 2010. "The Relationship of 'Systems Thinking'to Action Research." Systemic Practice and Action Research 23 (4):269-284.

Forrester, J. W. 1971. World Dynamics. Cambridge, Mass: Wright-Allen Press.

Gharajedaghi, J. 2006. Systems Thinking Managing Chaos and Complexity: A Platform for Designing Business Architecture 2nd ed. ed. Boston: Elsevier.

Godfrey, P. 2010. How Systems Thinking Contribute to Systems Engineering. INCOSE UK.

Gorelik, G. 1983. "Bogdanov's Tektology: Its Nature, Development and Influence." Studies in Soviet Thought 26 (1):39-57.

Hammond, D. 2003. The Science of Synthesis: Exploring the Social Implications of General Systems Theory. Colorado: the University of Colorado.

Heidegger, M. 1973. Being and Time. Oxford: Basil Blackwell.

Hung, W. 2008. "Enhancing Systems-Thinking Skills with Modelling." British Journal of Educational Technology 39 (6):1099-1120.

Jackson, M. C. 1985. "Social Systems Theory and Practice: The Need for a Critical Approach." International Journal of General Systems 10 (2-3):135-151.

- 1989. "Which Systems Methodology When? Initial Results from a Research Program." In Systems Prospects: The Next Ten Years of Systems Research, edited by R. Flood, Jackson, M., Keys, P. , 235-242. New York: Plenum.

1991. "The Origins and Nature of Critical Systems Thinking." Systems Practice 4 (2):131-149.

Jackson, M. C. 2000. Systems Approaches to Management: Kluwer Academic/Plenum Publishers. 
Jackson, M. C. 2001. "Critical Systems Thinking and Practice." European Journal of Operational Research 128 (2):233-244.

2006. "Creative Holism: A Critical Systems Approach to Complex Problem Situations." Systems Research and Behavioral Science 23 (5):647-657.

- 2009. "Fifty Years of Systems Thinking for Management." Journal of the Operational Research Society 60:S24-S32.

Johannessen, J. A. 1998. "Organisations as Social Systems: The Search for a Systemic Theory of Organisational Innovation Processes." Kybernetes 24 (4).

Joseph, R., and C. M. Reigeluth. 2010. "The Systemic Change Process in Education: A Conceptual Framework." Contemporary Educational Technology 1 (2):97-117.

Kapsali, M. 2011. "Systems Thinking in Innovation Project Management: A Match That Works." International Journal of Project Management 29 (4):396-407.

Kasser, J., M. Frank, and Y. Y. Zhao. 2010. "Assessing the Competencies of Systems Engineers." 7th Bi-annual European Systems Engineering Conference (EUSEC), Stockholm, Sweden, May 23.

Kellam, N., J. Walther, and A. Babcock. 2009. "Complex Systems: What Are They and Why Should We Care?" 116th Annual Conference \& Exposition, Austin, Texas, 14-17 June.

Kline, S. J. 1995. Conceptual Foundations for Multidisciplinary Thinking. California: Stanford University Press.

Koller, J. M. 1970. Oriental Philosophies. New Yourk: Charles Scribner's Sons.

Kossiakoff, A., and W. N. Sweet. 2011. Systems Engineering Principles and Practice. Edited by A. P. Sage. 2nd ed, Willey Series in Systems Engineering and Management. Hoboken, N.J: Wiley-Interscience.

Kunc, M. 2008. "Using Systems Thinking to Enhance Strategy Maps." Management Decision 46 (5):761-778.

Lamb, C. M. T. 2009. "Collaborative Systems Thinking: An Exploration of the Mechanisms Enabling Team Systems Thinking." Doctor of Philosophy, Department of Aeronautics and Astronautics, Massachusetts Institute of Technology.

Lane, D. C. 2016. "What We Talk About When We Talk About \&\#8216;Systems Thinking." J Oper Res Soc 67 (3):527-528.

Lane, D. C., and M. C. Jackson. 1995. "Only Connect! An Annotated Bibliography Reflecting the Breadth and Diversity of Systems Thinking." Systems Research 12 (3):217-228.

Laszlo, E. 1971. "Systems Philosophy." In Systems Thinking, edited by G. Midgley. London, Thousand Oaks, New Delhi: Sge Publications. Original edition, "Systems Philosophy," Ervin Laszlo, Main Currents in Modern Thought, 28, 55-60. (1971).

Luoma, J. 2009. "Systems Intelligence in the Process of Systems Thinking." Master of Science in Technology, Faculty of Information and Natuural Sciences, Helsinki University of Technology.

MacFadden, R. J., and D. Schoech. 2010. "Neuroscience, the Unconscious and Professional Decision Making: Implications for Ict." Journal of Technology in Human Services 28 (4):282-294.

Midgley, G. 2008. "Response to Paper "Systems Thinking" by D. Cabrera Et Al.: The Unification of Systems Thinking: Is There Gold at the End of the Rainbow?" Evaluation and Program Planning 31 (3):317-321. 
Mingers, J., and L. White. 2010. "A Review of the Recent Contribution of Systems Thinking to Operational Research and Management Science." European Journal of Operational Research 207 (3):1147-1161.

Nguyen, N. C., D. Graham, H. Ross, K. Maani, and O. Bosch. 2012. "Educating Systems Thinking for Sustainability: Experience with a Developing Country." Systems Research and Behavioral Science 29 (1):14-29.

Nodoushani, O. 1991. "What Systems Thinking Can Learn from History." Systems practice 4 (1):5-19.

Nychka, J. A., and J. J. Kruzic. 2013. "Design of Biomaterials: The Balancing Act between Reductionism and Systems Thinking." JOM 65 (4):469-472.

Owens, J. 1959. A History of Ancient Western Philosophy. New York: Appleton-Century-Crofts.

Quartz, S. R. 2009. "Reason, Emotion and Decision-Making: Risk and Reward Computation with Feeling." Trends in Cognitive Sciences 13 (5):209-215.

Ramage, M., and K. Shipp. 2009. Systems Thinkers. Springer: London.

Richmond, B. 1994. "Systems Thinking/System Dynamics: Let's Just Get on with It." System Dynamics Review 10 (2-3):135-157.

Rudall, B. H. 1998. "Contemporary Systems and Cybernetics." Kybernetes 27 (2):119-133.

Schiuma, G., D. Carlucci, and F. Sole. 2012. "Applying a Systems Thinking Framework to Assess Knowledge Assets Dynamics for Business Performance Improvement." Expert Systems with Applications 39 (9):8044-8050.

Schwaninger, M. 1997. "Integrative Aystems Methodology: Heuristic for Requisite Variety." International Transactions in Operational Research 4:109-123.

Senge, P. M. 2006. The Fifth Discipline: The Art and Practice of the Learning Organization. London; Sydney: Random House.

Sterman, J. D. 2000. Business Dynamics: Systems Thinking and Modeling for a Complex World. Vol. 19: Irwin/McGraw-Hill Boston.

Systems Engineering Competencies Working Group INCOSE-UK. 2010. Systems Engineering Competencies Framework. 2010. San Diego, California: International Council of Systems Engineering (INCOSE).

Trochim, W. M., D. A. Cabrera, B. Milstein, R. S. Gallagher, and S. J. Leischow. 2006. "Practical Challenges of Systems Thinking and Modeling in Public Health." American Journal of Public Health 96 (3):538.

Ulrich, W. 1983. Critical Heuristics of Social Planning: A New Approach to Practical Philosophy. Bern: Haupt.

Vallee, R. 2003. "Cybernetics and Systems, from Past to Future." Kybernetes 32 (5):853-857.

von Bertalanffy, L. 1968. General System Theory-Foundation Development Application. New York: Allen Lane The Penguin Press.

Walker, P. A., R. Greiner, D. McDonald, and V. Lyne. 1998. "The Tourism Futures Simulator: A Systems Thinking Approach." Environmental Modelling and Software 14 (1):59-67. 
Wang, Z. 2003. "Systems Intuition: Oriental Systems Thinking Style." Journal of Systems Science and Systems Engineering 12 (2):129-137.

Werhane, P. H. 2002. "Moral Imagination and Systems Thinking." Journal of Business Ethics 38 (1-2):33-42.

Whitehead, N. P., W. T. Scherer, and M. C. Smith. 2014. "Systems Thinking About Systems Thinking a Proposal for a Common Language." Systems Journal, IEEE PP (99):1-12.

2015. "Systems Thinking About Systems Thinking a Proposal for a Common Language." IEEE Systems Journal 9 (4):1117-1128.

Wiener, N. 1948. "Cybernetics." In Systems Thinking, edited by G. Midgey. London: SAGE. Original edition, "Cybernetics", Norbert Wiener, Scientific American, November 1948, 14-19 (1948).

Wright, C. 2013. "Multiple Systems Thinking Methods for Resilience Research." MPhil, Cardiff University.

Yeo, K. T. 1993. "Systems Thinking and Project Management-Time to Reunite." International Journal of Project Management 11 (2):111-117.

\section{Biography}

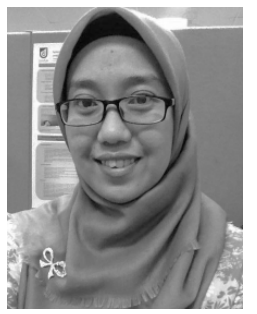

Fanny Camelia received the degrees B.Eng (Industrial), Andalas University, Indonesia in 2003 and M.AppPrjMgmt (Defence), the University of Adelaide, Adelaide, SA in 2011. She is currently working toward the Ph.D. degree in systems engineering at the School of Engineering, University of South Australia, Mawson Lakes, Australia.

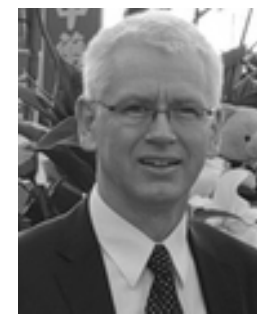

Timothy L.J. Ferris holds the degrees B.E.Hons, B.Th., B.Litt.Hons., GradCertEd, and $\mathrm{PhD}$, University of South Australia. He worked as an Engineer for the Electricity Trust of South Australia before becoming a faculty member in University of South Australia, at Mawson Lakes, South Australia, in 1991. By the time of publication of this paper, he is of faculty at Cranfield University, UK. Dr Ferris is a member of INCOSE. He is an Associate Editor of IEEE Systems Journal. 